\title{
OS CENTROS DO PODER ECONÔMICO MUNDIAL NA ATUALIDADE E AS POSSIBILIDADES DE CONFLITOS REGIONAIS
}

\author{
Luiz Fernando Vescovi ${ }^{1}$
}

\section{Resumo}

A presente pesquisa tem por intuito investigar as fontes primordiais de poder econômico mundial da atualidade, sob um enfoque geopolítico e das relações internacionais contemporâneas, e que detenham representatividade nas questões político-econômicas e administrativas de poder do globo, tendo por análise, também, as possibilidades de conflitos regionais decorrentes do crescimento destes centros. Tem por escopo, ainda, traçar, em linhas gerais, as evidências fáticas que este poder econômico mundial possa vir a ensejar num futuro internacional próximo, pelas relações que acontecem entre os Estados e pelos interesses que expressam, no cenário mundial.

\footnotetext{
1 Professor dos cursos de Direito e de Ciências Contábeis da UNOESC - Universidade do Oeste de Santa Catarina Campus Videira; mestre em Direito Internacional pela USC - Universidad San Carlos (Paraguai); especialista em Geopolítica e Relações Internacionais pela UTP - Universidade Tuiuti do Paraná; MBA (Master in Business Administration) em Comércio Internacional pela FATEC INTERNACIONAL - Faculdade de Tecnologia Internacional; bacharel em Direito (hab. Direito Empresarial) pela UP - Universidade Positivo; pesquisador em Contratos Internacionais e Arbitragem pela UFPR - Universidade Federal do Paraná (2005) e em Direito Internacional Econômico pela ABDCONST - Academia Brasileira de Direito Constitucional (2006); Advogado. E-mail: luizfernandovescovi@hotmail.com
} 
108 I InterAção

Palavras-chave: Poder econômico - conflitos regionais - relações internacionais.

Abstract

This research is meant to investigate the primary sources of world economic power today, a focus on geopolitical and contemporary international relations, and which have representation in political and economic issues and administrative power of the globe, with the analysis, too, the potential for conflicts arising from the growth of these regional centers. Its scope also outline, in general, the factual evidence that the world economic power is likely to give rise in a future international neighbor, the relationships that occur between the states and the interests they express on the world stage.

Keywords: Economic power - regional conflicts - international relations.

\section{INTRODUÇÃO}

O verdadeiro cenário internacional, hoje observado e investigado pelos analistas internacionais e geopolíticos contemporâneos, em nada se mostra, sequer analogamente, àquele mundo tido há algumas décadas atrás, pelo fato de os países e os momentos mundiais mudarem e transformarem-se, atualmente, numa velocidade tamanha e, por vezes, de difícil compreensão e/ou aceitação. Isso se pode afirmar, de maneira categórica, por haver interesses diversos e buscas por poder a todo o tempo, o tempo todo, pelos Estados que detém maior consoli- 
InterAção | 109

dação econômico-administrativa e financeira, no mundo.

A idéia, portanto, de "centros de poder mundial" remonta deste há muitos séculos, dos pontos de vista histórico e sociológico, e que vêm aprimorando, sua conceituação, com o progresso e com novos acontecimentos que o cenário mundial acaba por sofrer. Neste sentido é que se compreende a concretização de Estados ou blocos econômicos como a verdadeira formação de centros donde o poder mundial (de toda ordem) emana.

As conquistas que certos países detiveram, no passado e, alguns, no presente, reafirmam o ensejo de se angariar o poder em suas mãos, com a voluntas de comandar e dominar certo espaço geográfico mundial, com seus intentos sociais, econômicos, tecnológicos e bélicos. Com essa vontade trazida no bojo de países - quase sempre tidos de "primeiro mundo" - criam-se os conhecidos "centros de poder mundial", que são o cerne do presente trabalho e se formam quando da aglutinação do poderio, de forma hegemônica, alcançada a partir de intensos conflitos para se estabelecer uma ordem na qual estes "centros" (Estados com grande poder) ditam àqueles Estados desprovidos desta capacidade/força e, por razões de dominação, estes últimos acabam por mostrarem-se "dependentes" dos grandes centros de poder econômico mundial.

Por essa razão é que se tem o foco da pesquisa como uma averiguação aos centros contemporâneos de poder, em âmago supranacional, com o fim precípuo de compreender quais as razões, de fato, do porque existem países que conseguem atingir este status e, consequentemente, gerenciar grande monta do globo, sob sua égide de interesses. 
110 | InterAção

\section{0 poderio hegemônico dos Estados Unidos: a superpotência mundial}

No que se refere à única superpotência mundial atual, esta não poderia deixar de representar o maior de todos os centros de poder no mundo - em todos os sentidos -, tanto de cunho social, econômico, militar, tecnológico, dentre outros. Vários são os autores (pode-se citar: Immanuel Wallerstein, Joseph S. Nye Jr., dentre outros) que, por muitas vezes, já publicaram seus entendimentos sobre a ascensão estadunidense como superpotência internacional e detentora de grande parte (25\%) das riquezas produzidas no globo, bem como do consumo exacerbado das fontes naturais de recursos.

O forte armamento bélico e a inserção do soft power (poder brando) - este último chegando, por vezes, a um estágio de hard power (poder duro) - coadunam com a influência supranacional que os Estados Unidos mantêm no mundo. O poder econômico, muito bem simbolizado nas então torres do World Trade Center, com toda a sua reafirmação de austeridade e supremacia na qual jamais alguém viria a colimar, demonstrou, ao mundo, que, embora abalado com os ataques de 11 de setembro de 2001, o país se reergueu e hoje se apresenta, novamente, como consolidado centro de poder econômico-financeiro mundial. A nação norte-americana assim se mostra e autodetermina acerca de sua cultura: de uma forma tal que, sob abalo ou tensão mediatista, jamais irá se abalar, pois seu Estado é forte, central e detentor de todo e qualquer poder, donde nada, nem ninguém, poderá deixá-lo, um dia, obsoleto.

A astúcia e o domínio do povo estadunidense - no que concerne a uma hegemonia e luta por engrandecimento tal - os coloca- 
ram como o cerne dos diversos poderes existentes e conhecidos, sob o enfoque do domínio e exploração de outros países, face ao mundo que assim o assiste. Neste sentido, não há o que se questionar do já tão estudado e analisado país “superpotente” do mundo, senão a afirmação de que a sua hegemonia e poderio são tão grandes e evidentes que os Estados Unidos, sob certa ótica, acabam por gerenciar quase que todo o globo terrestre, quando das decisões que auferem, em especial quando grande parte dos órgãos e organismos internacionais é, por eles, administrada.

Destarte, a essência do poder norte-americano, sob a égide do intuito de se fazer como o efetivo e máximo centro de poder econômico mundial se explica, claramente, nas palavras de Demétrio Magnoli e Regina Araujo, quando explanam suas idéias em consonância com o crescimento ativo e implacável no que tange às indústrias, desde a segunda metade do século XIX, reafirmando tal poderio, de hoje, nas fontes históricas favoráveis:

Até a Primeira Guerra Mundial (1914-1918) viveu ainda o ciclo de crescimento iniciado na segunda metade do século XIX, baseado nas indústrias do aço e dos motores a combustão interna, na eletricidade e no petróleo. Esse ciclo foi interrompido por uma seqüência de crises agudas, cujo ponto extremo foi a Grande Depressão de 1929. Depois da Segunda Guerra Mundial (1939-1945) o crescimento capitalista foi retomado sobre novas bases, reativando a produção e a circulação de mercadorias.

Ao longo desses dois ciclos diferentes de crescimento do capitalismo, os Estados Unidos firmaram-se como a principal potência econômica do 
112 | InterAção

século. Na verdade, já em 1900, a produção industrial americana ultrapassava a britânica. Nas vésperas da Crise de 1929, os Estados Unidos atingiam uma dianteira folgada, que seria um pouco atenuada pelos efeitos da Depressão. (MAGNOLI; ARAUJO, 1991, p. 65).

Ainda, no entendimento notório de toda a população mundial, porém, literalmente explanado por José William Vesentini, tem-se a certeza de que grandes organismos internacionais, gerenciados diretamente pelos Estados Unidos - tais como o BIRD e o FMI, dentre outros - consolidam, de vez, a projeção estadunidense de poder central do mundo, atualmente, in verbis:

O FMI surgiu no final da Segunda Guerra Mundial juntamente com seu irmão gêmeo, o BIRD - Banco Internacional para Reconstrução e Desenvolvimento -, também conhecido como Banco Mundial e igualmente sediado em Washington. Tanto o BIRD como o FMI são instrumentos financeiros controlados pelos países ricos, especialmente os Estados Unidos. $\mathrm{Na}$ realidade, essas duas instituições pertencem à ONU e centenas de países possuem cotas e participam delas. (grifos nossos). (VESENTINI, 1992, p. 64).

Assim, tendo os Estados Unidos como a cúpula mundial de poder, na atualidade, nada de novo se tem a afirmar senão o reconhecimento de que seu poder e prestígio, no cenário internacional, são válidos e de autenticidade absoluta. A hegemonia do país, portanto, trouxe tal título àquele único, no momento atual, tido por "superpotência". 
InterAção | 113

\section{0 bloco econômico da União Europeia e sua influência mundial: o poder econômico dos países desenvolvidos}

A União Européia, bloco econômico formado por países do Velho Mundo, oriundo da então CEE - Comunidade Econômica Européia, de 1958, se apresenta, da maneira mais "avançada" que se conhece, na prática, como um efetivo bloco (conglomerado) de países, em comunidade - sistema de cooperação - para um desenvolvimento uno. Sua moeda é única (Euro) e o livre comércio de pessoas e serviços favorece esse tipo de transação e cooperação internacional.

Ocorre que, mesmo havendo uma intenção forte de se efetuar um bloco rico e consolidado no continente europeu, a União Européia vem passando por crises de grande relevância - em especial no que concerne à dificuldade em se conseguir implantar uma Constituição única, por haver resistência de alguns países (Holanda e França). Outro fator importante a se ressaltar, acerca do bloco, é a sua relativa "ineficiência" no aspecto estratégico-militar, segundo afirmam, a seguir, Angela Corrêa Krajewski, Raul Borges Guimarães e Wagner Costa Ribeiro:

Embora muitos analistas apontem a União Européia - bloco formado por países europeus - como uma potência mundial, isso não se confirma do ponto de vista estratégico-militar. Se é verdade que sua população representa um grande mercado consumidor, que supera o dos Estados Unidos, e que o euro (moeda da União Européia desde janeiro de 1999) pode vir a se tornar uma alternativa para as transações internacionais nos campos 
114 | InterAção

\begin{abstract}
financeiro e econômico, a União Européia ainda não conseguiu constituir forças armadas unificadas, principal termo de comparação quanto à capacidade de influência no mundo. (KRAJEWSKI; GUIMARÃES; RIBEIRO, 2003, p. 106).
\end{abstract}

Entretanto, como um bloco de esfera econômica e de poderio efetivo - núcleo do presente trabalho - e em negativa ao que se explana acima, não se tem como negar, hoje em dia, a UE como sendo um dos verdadeiros centros de poder mundial. Essa assertiva fundamenta-se no fato de que os países da União Européia são realmente os grandes detentores do poderio, no continente, ou seja, Estados ricos desde há muitas décadas, por si só, se aglutinando para fortalecerem ainda mais sua pretensão de riqueza e poder, frente à grande potência mundial (EUA) certamente acabou por trazer um bloco forte e de cunho econômico-financeiro rígido e concreto.

Tendo a Alemanha como líder da UE e a França como sendo a "vice-líder" do bloco, a tendência deste é o progresso intenso de trabalho e favorecimento dos países, num sistema de cooperação. É certo que estes dois Estados mencionados já se apresentavam fortes há anos atrás, assim, como grande parte dos países que da União Européia fazem frente, por esse sentido é que, com a unificação de nações já previamente fortes e detentoras de poder - cada qual com o seu - não poderia deixar de ser diferente o crescimento do poderio, quando da efetivação do bloco, centrando-se, desse modo, o poder das nações num único núcleo, formando uma potência, e, consequentemente, um verdadeiro centro de poder mundial

O cunho desenvolvimentista do bloco europeu é facilmente perceptível e estudado por especialistas na área da geopolítica e 
das relações internacionais; de importante menção acerca do ocorrido no processo integrativo do Velho Mundo, tem-se as palavras de José William Vesentini:

Um dos principais fundamentos dessa interpretação foi o sucesso da integração européia, cujo exemplo foi parcialmente imitado em várias partes do mundo (Nafta, Mercosul, Apec, as tentativas de se criar a Alca - Área de Livre Comércio nas Américas etc.). Nos anos 1980 alguns autores, e inúmeros jornalistas, falavam em "fortaleza européia", sugerindo um progressivo fechamento do continente com o avançar da integração. A partir daí, muitos começaram a interpretar como "natural" a formação de mercados regionais nos diversos continentes, vendo nesse processo o nascimento de uma nova ordem geopolítica mundial "plural", marcada pelas associações de países ao redor de um Estado núcleo ou central. Alguns dos adeptos dessa interpretação, exagerando a importância desses mercados regionais (e inclusive os homogeneizando, não percebendo as suas diferenças e vendo todos a partir do prisma da União Européia, o único que caminha de fato no sentido de construir uma confederação), passaram a falar numa "nova geografia regional do mundo" ou até mesmo em "blocos internacionais de poder". (VESENTINI, 2003, p. 36-37).

Fica evidente, portanto, que o bloco regional da Europa se convalida como um centro concretizado de poder econômico mundial, em especial pelo fato de sua integração ter sido efetuada de maneira cautelosa, seguindo a um patamar de confederação. Neste sentido, tal como os Estados Unidos, a UE explicita suas vontades de maneira austera e, por vezes, imperativa ao globo, perfazendo justamente o estereótipo de um núcleo que detém o poderio e o domínio, 
116 | InterAção

sob outros países. O seu fortalecimento, logo, deu-se com o sistema de integração e cooperação entre Estados, gerando forte e arraigada confiança de poder mundial.

\section{A China e seu poderio em constante ascensão: crescimento industrial acelerado}

O Estado chinês, localizado em ponto estratégico favorável da porção asiática do globo detém seu domínio como forma de poder no setor da mão-de-obra intensa e barata e população de alta densidade, passando de 1.000.000.000 (um bilhão) de pessoas, donde se tem produção de bens e produtos a todo instante, de forma ininterrupta. A China, portanto, é um verdadeiro império do poder comercial, especialmente no que tange aos produtos de segunda linha, conhecidos por "piratas" ou falsificados. O crescimento, como país, no ano de 2006 mostrou-se na ordem de 11\% (onze por cento), contra menos de $1 \%$ (um por cento) do crescimento brasileiro, por exemplo.

Neste sentido é que se acredita num boom chinês nos próximos anos, no que se refere à questão econômica, principalmente por haver esse tipo de crescimento populacional sem precedentes, juntamente com questões de ordem política (imperialismo exacerbado, administrando (o país) com "mãos de ferro") e os fatores de cunho nuclear (bombas e artefatos produzidos pelos chineses, neste segmento). Assim, observa-se a China, sob o ponto de vista desenvolvimentista:

A China é a economia que mais vigor tem demonstrado nas últimas décadas, com níveis constantes de crescimento. Isso se deve ao fato de ter conseguido 
a posição de parceiro comercial preferencial dos Estados Unidos, o que a favorece enormemente. Nessa condição, empresas norte-americanas recebem financiamento para se instalarem na China, embora os investimentos também cheguem de outros países, como do Japão. (KRAJEWSKI; GUIMARÃES; RIBEIRO, 2003, p. 110).

O poderio chinês, portanto, é vasto e digno de estudo criterioso por nunca ter tido um domínio de mercado - aqui, eminentemente no sentido econômico-comercial - tal como hoje ocorre neste Estado. As parcerias existentes, conforme explanado acima, mesmo criando certos atritos, atualmente, como em problemas de propriedade intelectual (patente de produtos, etc.) ainda se mostra em voga, tanto que há pouco tempo atrás o próprio Estado norte-americano negociou a fórmula secreta do refrigerante "Coca-cola" com a China devido a sua alta lucratividade, em vendas, naquele país, expressando ser um emergente mercado e centro de poder mundial, em expectativa comercial, dentre outros.

Tendo por embasamento e compreendido seu domínio mundial de mercado, analisa-se o ponto geopolítico-militar da nação chinesa. Neste aspecto duas passagens são interessantes de se avençar; a primeira dos professores antes citados e a segunda, de Craig Smith, sobre a forte potência bélico-militar que a China detém:

Um país que detém o maior exército do mundo (cerca de 2,5 milhões de homens), é potência nuclear, participa como membro permanente do Conselho de Segurança da ONU e tem a maior população do planeta - cerca de 1,3 bilhão - deve ser considerado quando se discute o sistema internacional. Não bastassem esses aspectos, a China tem 
118 | InterAção

atraído investimentos de diversos países, além de desenvolver tecnologias de ponta, como a produção de satélites artificiais e foguetes. (KRAJEWSKI; GUIMARÃES; RIBEIRO, 2003, p. 110).

Uma nova geração de generais chineses está remodelando as inchadas e superadas forças armadas da China, transformando-as numa força de combate moderna e integrada que está emergindo como potência regional, dizem especialistas ocidentais. A longo prazo, a meta é criar uma força capaz de projetar o poderio da China para muito além de sua costa. (SMITH, 2003, p. 112).

Perceptível é, portanto, que a China, mesmo em um governo tido, ainda, ditatorial, apresenta, hoje em dia, o capitalismo como uma constante dentro do Estado e com forte intuito de se tornar - como está caminhando para ser - um país dominador e de poderio sobre as nações vizinhas, ou até mesmo em parte do mundo. A expansão "exagerada" que o mundo assiste, por parte da China, tal como seu desenvolvimento e crescimento militar acabam por assustar países de outras partes do globo, devido à instabilidade e falta de precedentes de um progresso como tal. Por isso, o Estado chinês, percebendo tal alarde mundial frente à sua expansão, se fortalece nos segmentos que mais detém especialidade, angariando força e poder, com status de nação consolidada - ou em consolidação repentina - colocando-se no rol dos grandes centros de poder mundial do século XXI.

Por fim, se tem a China como a grande nação em discussão, na atualidade, pelos geopolíticos e analistas internacionais justamente pelo contexto em que se encontra e, em especial, pelo futuro incerto que ela irá demonstrar, no cenário supranacional, mas, sem deixar de ostentar o título de ser um dos centros mundiais de poder, este que, 
InterAção | 119

por vez, por anos vem sendo o objetivo chinês, com tais crescimentos comercial, tecnológico e desenvolvimentista.

\section{0 centro de poder russo oriundo da antiga ex-URSS: tecnologia bélica ainda respeitada}

Outro Estado que também expressa importância no cenário internacional como sendo um centro de poder mundial - hoje já mais relativizado pela sua essência capitalista - é a Rússia. Quando ainda integrava o bloco da extinta URSS - União das Repúblicas Socialistas Soviéticas, fazia frente ao poderio estadunidense na famosa dicotomia capitalismo x socialismo que foi exaurido com o fim da Guerra Fria, no final da década de 80 e início da década de 90.

Após o término da referida guerra, a nação russa entrou numa profunda crise política, na qual sofreu com questões de ordem econômica, dentre outras, entretanto, com sua força e garra advinda de seu cunho socialista da época passada, conseguiu estabilizar a situação, mas, em 1998, uma nova crise - intensa - se alojou na Rússia, agravando os problemas já existentes. Posteriormente, foi se recuperando, atingindo, hoje, o status de país primeiro-mundista. O poderio russo não apenas se mostra em seu arsenal bélico, ainda com resquícios do armamento socialista, mas também como sendo uma potência nuclear. Neste sentido tem-se as afirmações de Angela Corrêa Krajewski, Raul Borges Guimarães e Wagner Costa Ribeiro, in verbis:

Além de ser a principal potência nuclear depois dos Estados Unidos, a Rússia possui um dos maiores exércitos do mundo, o que lhe garante uma po- 
120 | InterAção

sição destacada no cenário internacional. Após a glasnost, entretanto, sua tecnologia bélica tornou-se inferior à da superpotência, o que a obriga a adotar táticas de guerra convencionais utilizando menos recursos eletrônicos. (KRAJEWSKI; GUIMARÃES; RIBEIRO, 2003, p. 108).

Mesmo com alguns percalços que a Rússia possa estar passando, o seu poderio é real, em especial no sentido regional, visto que os outros países de origem soviética detêm respeito e credibilidade à nação russa e seu domínio. Ainda, a força bélico-militar e tecnológica do Estado, mesmo tendo sido parcialmente destituído após a Glasnost, ainda merece consideração, pela importância histórica e contemporânea, e por expressar-se, portanto, como poder mundial centralizado.

Outro aspecto a ser ressaltado é a geografia política vantajosa (saídas para o Mar Mediterrâneo) que a Rússia expressa, bem como a relevante corrida espacial - que se fez por muitos anos - explicitando o poder tecnológico da nação. Por tal razão, reafirma-se, a Rússia, como importante centro de poder econômico mundial de hoje.

\section{0 centro de poder japonês: poder tecnológico mundial e líder asiático}

O Japão é um país eminentemente tecnológico e leva a cabo seu avançado centro de estudo e pesquisa neste setor. Grande parte do segmento mundial de tecnologia de ponta (robótica, em especial) tem origem neste Estado oriental. Ressalta-se, ainda, que o país enfrentou grandes tormentas em guerras, nas quais houve baixas, como ocorreu com as temíveis bombas atômicas despejadas nas cidades de Hiroshima e Nagasaki. 
InterAção | 121

Entretanto, seu crescimento - no que se refere à reconstrução do Estado -, após as guerras, aconteceu de maneira acelerada e bastante efetiva, investindo-se grandes somas em dinheiro nesta tão surpreendente tecnologia avançada que os japoneses detém. Com este poderio tecnológico-científico, tem-se a assertiva de que o Japão é sim um centro de poder mundial, neste e em outros setores, ainda hoje comandando, (acerca do domínio e da questão geográfico-político), o continente asiático, mesmo com o crescimento e a intervenção chinesa.

Célebres passagens sobre o Japão, sob um enfoque histórico, são descritas pelos professores Raul Borges Guimarães, Wagner Costa Ribeiro e Angela Corrêa Krajewski, que merecem destaque, enfatizando, de plano, a potência expansionista, o crescimento empresarial e o domínio do poder japonês, no continente onde se situa:

O Japão aparece como importante centro de produção tecnológica; entretanto, seu papel vai além. Empresas e grupos financeiros japoneses estão entre os maiores do mundo. A industrialização do Japão estruturou-se no final do século XIX. Antes disso, o país era dividido em xogunatos, sistema político fragmentado em domínios militares. Em 1868, com o enfraquecimento do sistema, o poder retornou às mãos do imperador Mutsuhito, iniciando-se a Restauração Meiji, período de significativa modernização. Estabeleceu-se uma Constituição e o ensino passou a ser obrigatório. Foram criados os Zaibatsus, grandes monopólios familiares concentrando indústrias e bancos, que se transformaram na base econômica do país. $\mathrm{O}$ fortalecimento econômico e militar resultante da Era Meiji alimentou o caráter expansionista do Japão. (KRAJEWSKI; GUIMARÃES; RIBEIRO, 2003, p. 111). 
Havendo, portanto, este caráter histórico de crescimento progressivo do poderio japonês, conjugado com seu domínio no setor tecnológico, todo o tipo de produto dessa natureza passa por um "aval" do país, o que lhe confere, por certo, o reconhecimento fático como sendo um "centro de poder econômico mundial", na atualidade.

\section{0 poder brasileiro frente ao bloco do MERCOSUL: sua influência na América Latina}

Não se pode deixar de mencionar a nação brasileira quando se trata de centros de poder mundial. Não que o Brasil detenha forte poder sobre muitos Estados, com o fim de se titulá-lo como centro mundial de poder econômico, militar e tecnológico, dentre outros, mas sim quando se trata do domínio efetivo que existe, por parte deste, sobre as nações do continente sul-americano. A força - diga-se de passagem: vasta, nos sentidos territorial, populacional e até mesmo financeiro - credita o Estado brasileiro a apresentar-se como centro de poder. Este centro, então, podendo expressar maior potência regional do que mundial, mas de relevância ao país, no cenário internacional.

Os tratados e/ou acordos internacionais ratificados para o Mercosul, por certo, tem o Brasil sempre (ou quase sempre) como signatário. Primeiro pelo fato de o país fazer parte do bloco da América do Sul e segundo pelo cunho desenvolvimentista e progressista que se tem, frente aos países do continente que, por vez, mostram-se menos favorecidos que o Brasil. Neste sentido, portanto, é possível afirmar o seu Estado como espécie regional de "centro de poder", sem 
InterAção | 123

deixar de mencionar os extensos recursos naturais que se encontram no território nacional, bastante visado pelos primeiro-mundistas.

Sendo, o Brasil, o maior Estado integracionista da América do Sul, este expressa seu poderio e dominação por sobre seus vizinhos, em especial pelo seu "expansionismo" no cenário internacional atual e por sua posição geopolítica e estratégia favorável. Neste norte, apontam-se as palavras de Manuel Correia de Andrade:

Sendo o Brasil um país de grande extensão territorial, de alto índice populacional e com o oitavo PIB do mundo, em 1996, não é de estranhar que ele tenha uma tendência a expandir a sua influência sobre os países vizinhos e/ou próximos. (ANDRADE, 2001, p. 80).

Ao Brasil, ainda, como país pacifista que é, tal como a posição marítima e continental privilegiada que expressa, não se tem dúvida de ser, de certo modo, um centro de poder mundial ainda em expansão e que, por sua vez, irá crescer muito ainda, devido aos seus recursos naturais e pela boa política da diplomacia internacional que apresenta, atualmente.

\section{Possibilidades de conflitos regionais}

Como se pode ter por base, analisando e avençando vários aspectos históricos e geográficos do mundo, em qualquer ponto ou momento em que o poder encontra-se em luta, para sustentar com quem este ficará, as possibilidades de conflito - armado ou não - são inevitáveis, isto é, em linhas gerais, o poder é "pressuposto" para se 
criarem agitações entre países, pelo interesse comum sob este último.

Mas é necessário ter em mente que, para haver uma certa disseminação do poder, principalmente quando um Estado-nação busca alcançá-lo - por medidas de domínio regional ou outra fonte - este estará situado em determinado lugar, preferencialmente central. Assim é que explana Claude Raffestin, em sua obra sobre a geografia do poder:

O poder, antes de se difundir e antes de se esgotar, se cristaliza num lugar, em lugares que com freqüência ele marca profundamente, às vezes até de uma forma indelével: "Há por que pensar que a verdade está inscrita na própria estrutura das comunidades, nos lugares centrais, a partir dos quais tudo irradia e que quase sempre constituem locais simbólicos de uma unidade coletiva cujo caráter original não devemos suspeitar, a priori, pois em geral é confirmado, ao menos em parte, pelas escavações arqueológicas". (RAFFESTIN, 1993, p. 186).

Mesmo havendo uma densa carga filosófica nas palavras do autor, é justamente assim que os Estados e blocos econômicos se comportam frente à possibilidade de angariar e deterem, para si, o poder propriamente dito. A incessante luta pelo poderio e hegemonia de um país por sobre o outro traz conseqüências, por vezes, desastrosas: guerras, conflitos entre civis, retaliações, falta de diplomacia, dentre outros. É neste momento que as possibilidades de conflitos regionais, e até mesmo, mundiais, podem vir a ocorrer.

Os atuais centros de poder mundial - de cunhos econômico, social, militar, tecnológico e político -, tal como as imposições que estes fazem ao mundo, embasados no domínio que atêm em suas mãos, causam furor àqueles desprovidos de tal favorecimento, geran- 
do problemas de ordem geopolítica e de guerrilha. Essas "formas" de furor podem se apresentar de diversas configurações e fundamentações: religiosa, discriminatória (social), política, etc.

Ao que parece, não existem maneiras de se exaurir o cunho conflituoso, (seja regional ou supra-regional), quando se fala de poder, dominação e hegemonia, precipuamente quando se tem poucos com tal ferramenta, ou seja, existindo algo que se poderia chamar de “oligárquica do poderio supranacional”, com poucos (Estados) mandando muito e em muitos (outros Estados), decorrente de sua fartura econômico-financeira, a aversão a estes é verdadeira e fática, sempre com um idealismo a fim de propulsar os conflitos, com a voluntas de "socializar" tal poder para outras nações do globo.

Onde há poder sempre haverá conflito. Nesta máxime pode-se sintetizar o que realmente acontece no mundo, atualmente, em nome da conquista do poderio e hegemonia face aos outros países, uma vez que é com o poder que tudo se alcança e, por conseqüência, tem-se o comando - senão total, ao mínimo parcial - do espaço geográfico universal.

A ira de alguns Estados embasa-se, por vezes, na forma de como o poder é ditado pelos grandes países, por não existir um consenso ou limitações ao seu uso - que hoje se mostra de maneira descontrolada e abusada - denegrindo (ou mesmo ridicularizando) as questões de crenças e/ou costumes daqueles. Neste ponto, tal como aconteceu com as caricaturas (charges) ao profeta Maomé, dos muçulmanos, causaram intensos conflitos, desordem e abalos, no momento, das relações internacionais diplomáticas entre os islâmicos e o Ocidente - matéria investigada por Alexsandro Eugenio Pereira -, como critério exemplificativo. 
In fine, os conflitos regionais por disputas de poder, tal como ocorre entre nações antagônicas e de ideologias diversas (p. ex. Israel e Palestina, ou Coréia do Sul e Coréia do Norte, ou outros) evidenciam o que o cenário internacional expressa hoje e como será o porvir acerca das relações internacionais contemporâneas. Que os problemas deixarão de existir por causa de poder isso jamais ocorrerá, mas um bom trabalho diplomático, feito com humanismo, tolerância e parcimônia, certamente acalentará eventuais problemas que possam ainda surgir, por implicação da luta e busca incessante do poder do mundo, entre as nações de primeiro-mundo.

\section{CONCLUSÃO}

Após verificação dos principais centros de poderio econômico-tecnológico e militar que o cenário mundial apresenta, contemporaneamente, é possível concluir que das manifestações, por parte destes Estados ou blocos, tem-se a direção de como e para onde está indo o progresso e o desenvolvimento do globo terrestre, uma vez que, as pesquisas científicas e os investimentos financeiros em tecnologia de ponta e em armamento militar (alguns dos fatores determinantes para se alcançar um status de país forte e investido de "poder" frente ao mundo) estão de posse destes países, e, por decorrência, detentores do futuro dos acontecimentos maiores, no plano supranacional.

Seus intentos - oriundos do poderio centrado que detém em mãos -, conjugado com a alta arrecadação de dinheiro e a possibilidade financeira de angariar recursos de países menos favorecidos economicamente, por todo o mundo, anseiam a proliferação de vontades 
que se fazem presentes, sem que hajam órgãos fiscalizadores para barrar até certas atrocidades que perpetram com as nações "pobres".

O poder, então, como pleito maior de toda nação, juntamente com a sua soberania absoluta e a independência de outras nações, é que efetivam a viabilidade de um país transformar-se em centro mundial de poder, donde se emanam, como bem se sabe, os "interesses do mundo". Neste sentido é que se afirma a busca plena e incessante de recursos financeiros e de origem da natureza, para deter reconhecimento e obediência como nação consolidada, possuidora de poderio válido e efetivo, no plano internacional, em face dos países desprovidos deste.

Certamente, os conflitos regionais, e até mesmo mundiais, por conta da "oligarquia" do poder, no mundo, são inevitáveis - em especial quando se tem insurgências religiosas, nucleares, consumeristas ou outros fatores que os proporcionam - em face destes que retém para si o tão almejado e buscado por todas as nações: o poder, propriamente dito. Os confrontos já são ferramentas utilizadas por muito tempo atrás, na esfera da geopolítica e das relações internacionais, com o fim de se conseguir uma harmonia e paz, sob o uso da força, entre Estados inimigos. Esta é a afirmação básica que constitui os conflitos regionais e mundiais, quando se tem o poder, o dinheiro e o domínio em jogo, pleiteado, seguramente, pelas nações conflitantes.

\section{REFERÊNCIAS}

ALMEIDA, Paulo Roberto de. Democratização do poder mundial: possível, realizável, imaginável ou simplesmente desejável? Site de Paulo Roberto de Almeida. Disponível em: <http://www.pralmeida.org/05Do csPRA//936DemocratizPoderMundial.htm>. Acesso em: 19.abr.2007. 
128 I InterAção

ANDRADE, Manuel Correia de. Geopolítica do Brasil. Campinas: Papirus, 2001.

CARVALHO, Leonardo Arquimimo de. Introdução ao estudo das relações internacionais. Porto Alegre: Síntese, 2003.

COELHO, Marcos de Amorim. Geografia geral: o espaço natural e sócio-econômico. - 3. ed. - São Paulo: Moderna, 1992.

FERREIRA JÚNIOR, Lier Pires. Estado, globalização e integração regional: políticas exteriores de desenvolvimento e inserção internacional da América-Latina no final do século XX. Rio de Janeiro: América Jurídica, 2003.

GUIMARÃES, Paulo César Milani. Centros mundiais de poder. RESERVAER. Disponível em: <http://www.reservaer.com.br/ estrategicos/centrosmundiais.html >. Acesso em: 23.abr.2007.

JACKSON, Robert; SORENSEN, Georg. Introdução às relações internacionais: teorias e abordagens. (Trad. Bárbara Duarte). Rio de Janeiro: Jorge Zahar, 2007.

KRAJEWSKI, Ângela Corrêa; GUIMARÃES, Raul Borges; RIBEIRO, Wagner Costa. Geografia: pesquisa e ação. - 2. ed. - São Paulo: Moderna, 2003.

MAGNOLI, Demétrio; ARAUJO, Regina. A nova geografia: estudos de geografia geral. São Paulo: Moderna, 1991.

PEREIRA, Alexsandro Eugenio. A relação do Ocidente com o Islamismo: da incompreensão à animosidade. Raízes Jurídicas, Curitiba, v. 2, n.2, jul./dez. 2006. Semestral. 
RAFFESTIN, Claude. Por uma geografia do poder. (Trad. Maria Cecília França). São Paulo: Ática, 1993.

SMITH, Craig. Pequim moderniza exército para ser potência militar. The New York Times. (Trad. Clara Allain). In: Folha de São Paulo, 20.nov.2002 apud KRAJEWSKI, Ângela Corrêa; GUIMARÃES, Raul Borges; RIBEIRO, Wagner Costa. Geografia: pesquisa e ação. - 2. ed. - São Paulo: Moderna, 2003.

VESENTINI, José William. Novas geopolíticas. - 2. ed. - São Paulo: Contexto, 2003.

Sociedade e espaço: geografia geral e do Brasil. - 22. ed. - São Paulo: Ática, 1992. 
130 | InterAção 